\title{
Abordagem para o Ensino da Lógica de Programação em Escolas do Ensino Fundamental II através da Ferramenta Scratch 2.0
}

\author{
Kauê T. N. Duarte ${ }^{1}$, Tatiane R. S. Silveira ${ }^{1}$, Marcos A. F. Borges $^{1}$ \\ ${ }^{1}$ Faculdade de Tecnologia - Universidade Estadual de Campinas (FT-UNICAMP) \\ Rua Paschoal Marmo, 1888 - Jd. Nova Itália, CEP:13484-332 - Limeira, SP, Brasil \\ \{kaue.duarte, tatiane.silveira\} epos.ft.unicamp.br, \\ marcosborgeseft.unicamp.br
}

\begin{abstract}
This paper presents a proposal of an approach to using Scratch application as a tool for learning and teaching. Despite the increasing application of games to education, inserting these subjects to schools remain challenging. The main goal is to set the importance in programming logic used to solve everyday problems, present in every students' life. In order to analyze its applicability, we chose two middle schools. Our findings demonstrated a clear improvement in both mathematical and logical skills. The students' motivation for working with games contributed to the approach acceptance.
\end{abstract}

Resumo. Neste trabalho é proposto uma abordagem para a utilização do Scratch como ferramenta para o ensino-aprendizagem nas escolas. Apesar da crescente aplicação de jogos para educação, inserir estes temas nas escolas ainda é um desafio. O objetivo principal é estabelecer a importância de utilizar a lógica da programação para a solução de problemas cotidianos, presentes na vida de todo estudante. A abordagem foi aplicada em duas escolas buscando analisar sua aplicabilidade. Os resultados obtidos indicam uma melhora dos alunos em quesitos como lógica e matemática. A motivação dos alunos por trabalhar com jogos facilitou a aceitação desta abordagem.

\section{Introdução}

A tecnologia pode ser definida como o ramo do conhecimento associado à criação e uso de meios técnicos e sua relação com a vida, sociedade e ambiente, baseando-se em assuntos como arte industrial, engenharia, ciência aplicada e ciência pura (Collins e Halverson, 2009). Atualmente, o uso da tecnologia pode ser observado em ações cotidianas, no qual são disponibilizadas ferramentas para o auxílio nas mais variadas questões, sejam elas utilizadas por crianças, jovens ou adultos. Uma das inserções possíveis da tecnologia é no ensino, público ou privado, como facilitador da relação ensino-aprendizagem (Alves e Bianchin, 2010).

O ensino é o ato ou processo de transmitir ou adquirir conhecimento, desenvolvendo nos interessados a capacidade de interpretação e julgamento das informações (Collins e Halverson, 2009). Em Toffler (1980) é relatado que a sociedade altera suas diretrizes com o passar do tempo, através do estilo familiar, de maneiras diferentes de realizar um dado trabalho, a política, e até mesmo a consciência das 
pessoas. Para que o ensino acompanhe estas mudanças da sociedade, ele deve se adaptar frequentemente com intenção de que a informação possa ser transmitida. Assim, o modo de ensino proposto a 10 ou 20 anos atrás pode não ser o mais adequado nos tempos atuais. É cada vez mais comum ver os alunos envoltos pela tecnologia, seja de porte pessoal ou mesmo provido pela escola. Neste contexto, a tecnologia costuma ser vinculada à dispersão dos alunos em sala de aula. No entanto, não há evidência de que, ao se retirar a tecnologia do ambiente escolar, o aluno irá aprender de forma mais eficiente. É pertinente definir uma relação entre tecnologia e ensino, no qual o objetivo seja o aluno dispor do mesmo desejo utilizado para entretenimento, com conteúdos encontrados em sala de aula.

Por mais que a tecnologia evolua, juntamente com o ensino, ainda é encontrada uma forte barreira que dificulta a cooperação entre essas duas áreas quando a relação é intra-aula. Vale ressaltar que esta barreira é um dos grandes desafios, que necessitam ser ultrapassados, para que haja tecnologia em sala de aula. Mais do que isso, é importante definir como a tecnologia interage em um ambiente educativo. Um dos modos disponíveis para a inserção da tecnologia em ambientes escolares é através de jogos que são, em uma definição mais ampla, uma atividade cuja natureza é a diversão e o entretenimento (Whitton e Moseley, 2012). De certa forma, os jogos oferecem aos estudantes desafios, cujas complexidades para solução vão aumentando no decorrer de suas missões. É este confronto que estimula o jogador (Gee, 2004). Através da análise feita em Gee (2004), a motivação é um dos fatores mais importantes para a aprendizagem, e formulando uma analogia entre jogos e a sala de aula, o estudante passa a não ser apenas um jogador, mas um criador, em uma situação na qual ele deve raciocinar para criar uma lógica para solucionar o problema, customizar o personagem, criar as missões, entre outros.

A inserção de jogos na educação ainda é algo a ser explorado, mesmo com a crescente demanda de trabalhos que vêm sendo propostos com o intuito de formular esta conexão entre a escola e a tecnologia. Em Martins (2016) é relatado o uso de diversos conceitos computacionais voltados a robótica via Lego Mindstorm EV3 para alunos do ensino fundamental. O objetivo principal é despertar nos alunos o interesse pela tecnologia, bem como a capacidade de resolver problemas através da lógica. Em Castro et al. (2016) é proposto um experimento do ensino de matemática através de algoritmos via jogos computacionais para alunos do ensino fundamental. O objetivo é potencializar o conteúdo aprendido diminuindo a lacuna entre a prática e a teoria.

Nota-se a necessidade de definir boas ferramentas que viabilizem o auxílio ao ensino. Dentre tais ferramentas, tem-se o Scratch, no qual os alunos utilizam a combinação de blocos de ações para representar uma determinada tarefa a ser executada. Em Silva et al. (2016) são propostas oficinas para que os alunos desenvolvessem a lógica de programação através da criação de aplicações via Scratch. Os desenvolvimentos envolviam tanto conceitos de ciência da computação quanto de lógica computacional. Em Andrade et al. (2016) é proposto uma oficina a fim de estimular a programação através de jogos digitais para alunos do ensino médio utilizando o Scratch. Os resultados foram combinados através da utilização de diversos critérios (e.g. Lógica, Controle de Fluxo, Sincronização), permitindo assim identificar quais foram as maiores defasagens da sala. Em Matsuzaki e Borges (2016) é proposta uma abordagem que utiliza ferramentas computacionais para auxiliar jovens e crianças 
na aprendizagem da lógica de programação. $\mathrm{O}$ objetivo é habilitar o aluno para que o mesmo desenvolva jogos sem a necessidade de programação via código, apenas utilizando blocos com ações pré-definidas. Esta abordagem, inclusive, tinha um vertente extraclasse, focando que o aluno teria não apenas o conhecimento para a criação de um jogo, mas também que ele conseguisse utilizar lógica para solução de outros problemas, que estão presentes no cotidiano de um estudante. A aprendizagem é desenvolvida através do jogo chamado "Era Uma Vez", elaborado em Scratch 2.0, no qual a Chapeuzinho Vermelho tem que percorrer trajetos para encontrar sua avó, evitando o encontro com o Lobo Mau.

A abordagem proposta neste trabalho baseia-se no trabalho de Matsuzaki e Borges (2016), apresentando as seguintes adaptações: 1) O número de escolas utilizadas para aplicação da abordagem; 2) as aulas sofreram modificações na forma de aplicação, questionando o aluno sobre qual tema ele gostaria de trabalhar, e não utilizando um previamente selecionado; 3) o modelo de avaliação e análise de resultados serão realizadas em duas vertentes, uma através da dinâmica das aulas e a outra dos questionários.

Este trabalho está organizado nas seguintes seções: Na seção 2 são apresentados os materiais e métodos utilizados por este trabalho. A dinâmica realizada nas escolas é relatada na seção 3. Na seção 4 são apresentados os resultados e discussões. Finalmente, na seção 5 é relatado as considerações finais e trabalhos futuros.

\section{Materiais e Métodos}

Para a criação do jogo, foi utilizado o software Scratch 2.0. Esta ferramenta possibilita ao aluno criar diversos tipos de aplicações sem a necessidade de programação via código, sejam elas histórias interativas, animações, simulações ou jogos. Dessa forma, é possível ao aluno desenvolver o seu ponto de vista sobre um determinado assunto. Uma das qualidades deste software é a sua distribuição multilinguagem, permitindo ao aluno a interação através de sua língua materna. Outro ponto que deve ser ressaltado é que o Scratch 2.0 possui versões Offline, i.e. o aluno instala o software em sua máquina local e desenvolve o projeto, e também a versão Online (Lab, 2013), na qual é permitido que o aluno desenvolva seus projetos em qualquer lugar, sem a necessidade de instalar o software cada vez que for utilizá-lo. A ferramenta permite a produção de seu conteúdo através da combinação de blocos que efetuam determinadas ações, sejam elas de movimento, controle, sensores, operações, entre outros.

Foram utilizados, para avaliação da abordagem proposta, três questionários que representam a análise quantitativa deste trabalho. $O$ Questionário 1 estabelece perguntas mais gerais, que podem ser agrupadas em três grupos: 1) Com respostas Sim ou Não: "Interessa-se por matemática?", "As aulas de matemática são interessantes?", "Fez algum curso de informática?", Fez algum curso de programação?", "Tem interesse por Computação?", "Você gosta do laboratório de informática?"; 2) Com respostas Muito, Mais ou Menos, Pouco, ou Nada: "Gosta de tecnologia?"; 3) Com respostas Estudar, Jogar, Ler Notícias e Fazer Pesquisa: "Em casa, você utiliza tecnologia para:".

O Questionário 2 consiste em um acompanhamento das aulas, ou seja, para cada aula, são definidas três perguntas. São elas: 1) Quanto você gostou da aula ;2) Quão 
VI Congresso Brasileiro de Informática na Educação (CBIE 2017)

Anais do XXIII Workshop de Informática na Escola (WIE 2017)

interessante foi a aula; e 3) Quanto você entendeu da aula? As questões são de múltipla escolha (Excelente, Bastante, Comum e Não muito).

O Questionário 3 consiste em perguntas para finalização da oficina, composta apenas de questões com alternativas Sim ou Não. São elas: "Interessa-se por matemática?", "As aulas de matemática são interessantes?", "Você gostaria de fazer algum curso de informática?", "Você gostaria de fazer algum curso de programação?", "Tem interesse por computação?", "Você tem interesse de continuar as aulas de programação Scratch?", "Você fez alguma pesquisa sobre Computação/Scratch/Programação durante a oficina?", "Tem alguma sugestão para a oficina?".

O grupo de monitores que aplicaram a oficina era composto por duas pessoas, no qual cada uma ficou responsável pela aplicação em uma determinada escola. Foram realizadas duas reuniões, uma no início e uma ao final do curso. A reunião inicial definia o encargo de cada monitor, i.e., gerenciar as aulas, os questionários, e o modelo de aplicação em cada escola. A reunião final foi realizada para debater e consolidar os resultados obtidos em ambas as aplicações.

Os temas necessários para capacitação dos alunos no entendimento da lógica de programação foram divididos em seis aulas, cada módulo correspondente a uma aula com uma hora de duração. A divisão dos temas, assim como abordagem em cada aula são mostradas na Tabela 1.

Tabela 1. Definição Geral da aplicação das aulas (Matsuzaki e Borges, 2016)

\begin{tabular}{|l|l|l|l|}
\hline Aula & Tema & Teórico & Prática \\
\hline 1 & Introdução & $\begin{array}{l}\text { Explicação dos termos: } \\
\text { Algoritmo e Programa }\end{array}$ & $\begin{array}{l}\text { Construir dentro de um tabuleiro } \\
\text { um desenho e seu Algoritmo }\end{array}$ \\
\hline 2 & $\begin{array}{l}\text { Algoritmo } \\
\text { no dia-a-dia }\end{array}$ & $\begin{array}{l}\text { Explicar a aproximação de } \\
\text { conceitos abstratos para } \\
\text { metáforas do mundo real }\end{array}$ & $\begin{array}{l}\text { Encontrar e descrever as } \\
\text { atividades do cotidiano em } \\
\text { Algoritmos }\end{array}$ \\
\hline 3 & $\begin{array}{l}\text { Sequência } \\
\text { de passos }\end{array}$ & $\begin{array}{l}\text { Formalizar a forma de de } \\
\text { representar a sequência de } \\
\text { passo descritas nos } \\
\text { algoritmos }\end{array}$ & $\begin{array}{l}\text { Apresentar os mecanismos de } \\
\text { "Movimento" e "Controle" da } \\
\text { ferramenta Scratch }\end{array}$ \\
\hline 4 & $\begin{array}{l}\text { Laços de } \\
\text { repetições }\end{array}$ & $\begin{array}{l}\text { Explicar que trabalhos } \\
\text { repetitivos podem ser } \\
\text { descritos em formas enxuta }\end{array}$ & $\begin{array}{l}\text { Apresentar os comandos de laços } \\
\text { de retição e resolução de } \\
\text { labirintos }\end{array}$ \\
\hline 5 & Depuração & $\begin{array}{l}\text { Demonstração que Algoritmo } \\
\text { pode estar: errado ou } \\
\text { incompleto. Neste caso, é } \\
\text { importante saber encontrar o } \\
\text { erro. }\end{array}$ & $\begin{array}{l}\text { Corrigir Algoritmos com erros } \\
\text { nas atividades do labirinto } \\
\text { usando o mínimo de trabalho } \\
\text { possível, ou seja, não é } \\
\text { interessante que seja refeito tudo } \\
\text { do zero }\end{array}$ \\
\hline 6 & $\begin{array}{l}\text { Revisão e } \\
\text { Condição }\end{array}$ & $\begin{array}{l}\text { Apresentar o conceito de } \\
\text { condição }\end{array}$ & $\begin{array}{l}\text { Exploração do funcionamento } \\
\text { dos comandos condicionais }\end{array}$ \\
\hline
\end{tabular}


VI Congresso Brasileiro de Informática na Educação (CBIE 2017)

Anais do XXIII Workshop de Informática na Escola (WIE 2017)

\section{Dinâmica das Aulas}

Esta seção relata a experiência de aplicação da abordagem proposta em duas escolas brasileiras de ensino fundamental II:

1. Escola 01 - Pública: aplicado em alunos do $7^{\circ}$ ano, situada na cidade Limeira$\mathrm{SP}$;

2. Escola 02 - Particular: aplicado em alunos do $6^{\circ}, 7^{\circ}$ e $8^{\circ}$ ano, situada na cidade de Campinas-SP.

Nesta seção são relatados os acontecimentos que ocorreram durante os dois cursos. Nas duas próximas subseções, são apresentadas, respectivamente, as observações referentes a Escola 01 e as observações realizadas para a Escola 02.

\subsection{Dinâmica na Escola 01}

As aulas foram lecionadas em duas semanas, com três aulas por semana, iniciando as $12 \mathrm{~h} 40 \mathrm{~min}$ e finalizando as $13 \mathrm{~h} 40 \mathrm{~min}$. Durante a primeira semana, houve a necessidade de aplicar a Aula 1, que precisou ser adiada por um imprevisto que ocorreu na escola, junto com a Aula 2. Portanto, as aulas 1 e 2 ocorreram no segundo dia planejado para aplicação, com cerca de 1h40min. Para melhor explicar a abordagem utilizada, este dia será dividido em duas partes: Aula 1 e Aula 2.

A Aula 1 , que foi programada para começar às $12 \mathrm{~h} 40 \mathrm{~min}$, teve início às $13 \mathrm{~h}$, pois houve o atraso de alguns alunos. Além disso, o curso era composto por duas turmas, porém apenas uma compareceu. A aula 1 durou cerca de $50 \mathrm{~min}$. Inicialmente, foi realizado a apresentação do monitor. Após a apresentação, houve a apresentação por parte dos alunos. Foi iniciado a explicação da parte conceitual, termos como algoritmo e programa. Ao final da parte conceitual, os alunos realizaram a atividade da Aula 1, que era elaborar o caminho para o preenchimento das células em um tabuleiro via instruções.

Com a finalização dos tabuleiros, iniciou-se a Aula 2, referente ao trabalho de geração dos algoritmos pelos alunos. Foi explicado rapidamente como transcrever os passos de um algoritmo, e passado então um exercício para que eles treinassem. $\mathrm{O}$ exercício consistia de realizar três algoritmos referentes a atividades cotidianas dos alunos. Os alunos fizeram as atividades desta aula rapidamente, ficando sob a responsabilidade do monitor dizer se o algoritmo feito pelos alunos estava de acordo com a realidade. $\mathrm{O}$ monitor se comprometeu a criar os e-mails para todos os alunos presentes na aula, pois para o acesso Online da ferramenta Scratch era necessário um email particular. A aula foi finalizada com 50min de duração.

A Aula 3 foi realizada no período das $12 \mathrm{~h} 40 \mathrm{~min}$ às $13 \mathrm{~h} 40 \mathrm{~min}$ do terceiro dia, conforme estipulado pela escola. Neste dia, compareceram 10 alunos, que haviam comparecido no dia anterior. A aula se iniciou com a explicação da ferramenta Scratch, suas técnicas e os procedimentos para realizar as ações. É importante notar que os emails exigidos para acesso Scratch já haviam sido criados anteriormente. Sobre a aula, houveram dois momentos em que o monitor teve que tomar posse da lousa, uma para explicar mapa cartesiano e a outra para mostrar os programas para geração dos sprites (personagens criados pelos alunos). As ações explicadas no Scratch foram: Movimento (define ações de localidade do personagem); e Aparência (define ações que apresente 
diálogo ou mudanças visuais). Ao final da aula, foi ensinado como salvar os arquivos e como baixá-los em um ambiente externo.

A Aula 4 foi realizada no primeiro dia da segunda semana, das $12 \mathrm{~h} 40 \mathrm{~min}$ às 13h40min, com 8 alunos. Nessa aula, os alunos receberam um template contendo uma parte do jogo "Era Uma Vez". O objetivo foi apresentar as diversas formas de solucionar o labirinto, bem como entender as estruturas disponíveis no Scratch. Foram apresentados dois tipos de blocos lógicos na ferramenta Scratch: blocos de repetição (evita ações que se repetem) e os blocos de condição (definem caminhos a serem seguidos). Nos últimos $20 \mathrm{~min}$ de aula, foi utilizado uma abordagem em uma vertente mais construtivista, ao qual foi solicitado que os alunos pensassem em um estilo de jogo, com personagens que eles gostariam de fazer.

A Aula 5 foi realizada no segundo dia da segunda semana, das $12 \mathrm{~h} 40 \mathrm{~min}$ às 13h40min, compareceram 6 alunos neste dia. Inicialmente, foi passado aos alunos presentes os questionários 2 e 3 . Eles responderam o questionário 2 até a aula 5 e o questionário 3 foi preenchido por completo. Ao final do preenchimento, houve uma explicação rápida sobre o conceito de depuração, e foi passado dois jogos de "Ache os 7 erros", disponibilizando 10 minutos para cada jogo. Após as explicações teóricas, foram apresentados dois problemas lógicos para serem solucionados pelos alunos, referentes a depuração de labirintos. Devido a falta de muitos alunos, houve uma estratégia de usar a aula como uma revisão.

A Aula 6 foi realizada no terceiro dia da segunda semana, no período das 12h40min às 13h40min. Compareceram 9 alunos neste dia. Para os alunos que haviam faltado no dia anterior, foi passado o questionário 3 para que eles preenchessem, e todos os alunos receberam o questionário 2, seja para preencher apenas a aula 6 , ou no caso dos alunos que faltaram na aula 5, preencherem todas as aulas que eles presenciaram. A aula que foi realizada focou-se em resolver um exercício de labirinto pré-estabelecido. Logo após, os alunos tiveram a liberdade de continuar alguns projetos que eles estavam tentando resolver. Para finalizar, houve a entrega dos certificados apenas para os 9 alunos que se mantiveram até o final do curso.

Algumas considerações são pertinentes sobre a aplicação das aulas na Escola 01: 1) As aulas ocorreram após o período letivo dos alunos, o que permitiu uma maior liberdade com relação aos horários fixados; 2) Durante o curso, houveram poucos alunos que desistiram (i.e. iniciando com 11 alunos e finalizando com 9); 3) O processo de seleção dos alunos foi realizado pela escola; 4) Todos os alunos que receberam o curso possuem 13 anos de idade.

\subsection{Dinâmica na Escola 02}

$\mathrm{Na}$ segunda dinâmica, as aulas foram lecionadas em seis semanas, com uma aula por semana, iniciando as $12 \mathrm{~h}$ e finalizando as $13 \mathrm{~h}$.

A Aula 1 foi aplicada na primeira semana conforme acordado com a escola. As tarefas apresentadas foram: a apresentação dos monitores e detalhes sobre curso; explicação do projeto; comprometimento entre aluno, monitor e coordenação pedagógica; informação sobre os dias e duração das aulas. Foi perguntado aos alunos se eles saberiam explicar a definição do que seria Tecnologia e os vocabulários que seriam usados (e.g. algoritmo e programa). Em seguida, foi apresentado o significado formal 
de cada conceito. Conforme as atividades programadas, foi aplicado o Questionário 1, e realizado o teste do tabuleiro. Foram criados e-mails para os alunos utilizarem a ferramenta Scratch online. A aula foi acompanhada por um professor da Escola 02.

A Aula 2 teve início com um atraso de 20min, que foi reposto no final. Inicialmente, foi realizado uma breve revisão da primeira aula para dar seguimento. Começou-se com o "Algoritmo BIS", i.e. o monitor seria como um robô segurando a caixa de BIS, e a sala iria escolher um representante entre eles para realizar os passos desde a aquisição da caixa de BIS até a sua abertura. Na sequência, os demais alunos escolheram um representante para relatar em papel o passo-a-passo realizado, no qual os comandos eram fornecidos pelo restante da turma. Ao final da tarefa, houve a distribuição do chocolate a cada aluno participante. Em seguida, foi distribuído o material para realizar o algoritmo dia-a-dia, no qual os alunos teriam que escolher três exemplos de eventos cotidianos para realizar a atividade. Foram sugeridos como exemplos como: escovar os dentes, tomar banho, fazer um achocolatado, entre outros. Foi aberta também a oportunidade para que os alunos escolhessem eventos que não estavam nos exemplos disponibilizados. Os alunos tiveram $15 \mathrm{~min}$ para que a atividade fosse completada. Como exercício de casa, os alunos receberam o encargo de definir o passo-a-passo da criação de um avião de papel.

A Aula 3 foi iniciada com a explicação dos comandos e da ferramenta Scratch. $\mathrm{O}$ conceito de movimento foi explicado e as tarefas que os alunos desenvolveriam (i.e. atravessar a Chapeuzinho Vermelho até a Vovozinha). Para compreenderem melhor o comportamento do movimento, foi necessário explicar sobre o plano cartesiano. O tempo de aula foi de aproximadamente $1 \mathrm{~h} 30 \mathrm{~min}$. Ao todo, participaram 10 alunos (alguns dos alunos não participaram por terem aulas de reforço no horário).

A Aula 4 foi iniciada as $12 \mathrm{~h} 30 \mathrm{~min}$ com a presença de 10 alunos. No início da aula foi colocado um ponto para reflexão sobre a dificuldade de precisar repetir comandos a fim de executar uma dada tarefa. Para isso, foi mostrado a abordagem do dia, que são os laços de repetições. As tarefas se resumiam em reestruturar os exercícios realizados nas aulas anteriores com as novas estruturas explicadas. Como as Aulas 4 e 5 foram realizadas no mesmo dia, não houve a necessidade de revisão do conteúdo para a Aula 5. Para explicar de forma intuitiva a ideia de depuração, utilizou-se dois jogos de "Ache os 7 erros", tendo sido disponibilizado um tempo para solucioná-los. Após a solução dos jogos estarem anotadas, foi definido o conceito de depuração. Muitos alunos já estavam criando seus próprios jogos em casa, utilizando a ferramenta ensinada.

A Aula 6 ocorreu na sexta semana. A aula iniciou-se com a revisão de todas aulas anteriores, como conceitos de algoritmo e programa, algoritmo dia-a-dia, mapa cartesiano, laços de repetições, depuração e criação de códigos para os templates da Oficina "Era uma Vez". Por fim, foi apresentado o conteúdo da aula, ou seja, as estruturas condicionais, encontradas com facilidade através dos blocos SE e SENÃO. Foi aplicado este conceito em três exercícios. Os questionários 2 e 3 foram aplicados, o primeiro para avaliar as aulas e o segundo para avaliar o projeto Scratch. Ao final, foram disponibilizados aos alunos os certificados do curso.

Alguns pontos merecem ressalvas. São elas: 1) A turma foi formada pelos gestores da escola; 2) Os alunos possuíam uma faixa etária de 11 a 13 anos; 3) O tempo 
de aula era bastante flexível, pois era permitido que a aula se estendesse em $50 \%$ de sua duração inicial; 4) $\mathrm{O}$ alto índice de desistências (i.e. iniciou com 16 alunos e finalizou com 7) deve-se a recuperação, realizada no mesmo período das aulas e ensaios.

\section{Resultados e Discussões}

Nesta seção serão apresentadas as análises realizadas durante a execução do projeto em ambas as escolas. As análises foram efetuadas através dos resultados obtidos nos três questionários aplicados.

A aplicação dos questionários seguiu o mesmo procedimento em ambas as escolas. Os questionários são apresentados a seguir, na seguinte sequência: 1) Análise Inicial, 2) Avaliação das Aulas, 3) Análise Final.

O primeiro questionário foi aplicado com a finalidade de identificar o quão envolto na tecnologia e nos assuntos que seriam abordados os alunos estavam. Para isso, foram elencadas algumas perguntas, e aplicadas no início da Aula 1. Foi identificado, em ambas as escolas, que 93,75\% dos alunos possuem interesse por tecnologia, apesar de $77 \%$ deles não terem realizado nenhum curso de informática. Na análise do motivo dos alunos utilizarem, ou estudarem tecnologia, é possível notar que a utilização para jogos obtém a maior porcentagem em ambas as escolas $(83,2 \%)$, o que viabiliza a inserção da abordagem proposta. O laboratório de informática é muito bem avaliado, com $98 \%$ de aprovação dos alunos.

O segundo questionário foi aplicado na última aula. Entretanto, desde a primeira aula foi pedido para que os alunos fizessem suas anotações. O questionário consistia de três perguntas para cada aula: 1) Quanto o aluno gostou da aula; 2) Quão interessante foi a aula; e 3) Quanto o aluno entendeu da aula. Para cada questão era disponibilizado quatro alternativas (Excelente, Bastante, Comum, Não muito). Através da análise do Questionário 2, é relatado que as aulas possuem um nível de aceitação superior a $85 \%$ em todos os quesitos, se for somado as classificações de Excelente e Bastante.

O terceiro e último questionário, aplicado na última aula, teve a finalidade de identificar quais foram as mudanças que ocorreram com os alunos no decorrer do curso. O primeiro e o último questionário possuem uma forte similaridade estrutural.

Com base no resultado final do questionário, algumas sugestões foram elaboradas pelas escolas, são elas: 1) Que o curso fosse estendido, a fim de permitir aos alunos a oportunidade de criar jogos mais elaborados; e 2) Que o curso fosse expandido para a aplicação às demais turmas da escola, pois os alunos ficaram bastante satisfeitos com a abordagem. É possível identificar também a grande aceitação que o Scratch obteve $(85,7 \%)$, e que aproximadamente $50,8 \%$ dos alunos deram continuidade na ferramenta fora do curso. Nota-se que houve a desistência de alunos em ambas as escolas aplicadas com 18,2\% e 52,2\% nas Escolas 01 e 02 , respectivamente. Houve um acréscimo obtido no quesito "Gostar de Matemática" $(18,12 \%)$. Inferiu-se que este aumento deve-se ao fato de que os alunos que continuaram no curso eram aqueles que possuíam maior afinidade com matemática. 
VI Congresso Brasileiro de Informática na Educação (CBIE 2017)

Anais do XXIII Workshop de Informática na Escola (WIE 2017)

\section{Considerações Finais}

A inserção da tecnologia no Ensino Fundamental II, em especial os jogos, permitem que os alunos aprendam conteúdos lecionados pela escola através de um modo interativo e lúdico. Não obstante, o uso da tecnologia em sala de aula permite que o aluno seja coorientador de seu aprendizado.

Neste trabalho foi declarado uma abordagem que ensina a lógica de programação para alunos do Ensino Fundamental II, sem a necessidade de ensinar a programação via código. Tal abordagem foi aplicada nas escolas através de uma oficina, ao qual os alunos de uma determinada série seriam acompanhados por um período de seis aulas. Os conteúdos lecionados variam desde conceitos, como algoritmos e programas, até estruturas, como condicionais e repetições.

Notou-se com a aplicação das avaliações uma melhora em diversos quesitos analisados durante o decorrer da oficina (e.g. lógica, matemática). Os alunos se mostraram bastante interessados com a dinâmica proposta por essa abordagem. Quanto mais eles se sentiam envoltos nas aulas, mais aprendiam o conteúdo que necessitava ser lecionado. Por fim, os projetos futuros elaborados vão desde a aplicação em mais níveis do ensino, como Ensino Fundamental I e Ensino Médio, até a expansão da oficina, podendo torná-la, inclusive como uma matéria optativa nas escolas.

\section{Referências}

Alves, L. e Bianchin, M. A. (2010). O jogo como recurso de aprendizagem. Revista Psicopedagogia, 27:282 - 287.

Andrade, R., Mendonça, J., Oliveira, W., Araujo, A. L., e Souza, F. (2016). Uma proposta de oficina de desenvolvimento de jogos digitais para ensino de programação. In Anais dos Workshops do V Congresso Brasileiro de Informática na Educação (CBIE 2016). Sociedade Brasileira de Computação - SBC.

Castro, M. C., Werneck, V., e Gouvea, N. (2016). Ensino de matemática através de algoritmos utilizando jogos para alunos do ensino fundamental II. In Anais dos Workshops do V Congresso Brasileiro de Informática na Educação (CBIE 2016). Sociedade Brasileira de Computação - SBC.

Collins, A. e Halverson, R. (2009). Rethinking Education in the Age of Technology: The Digital Revolution and Schooling in America. Teachers College Press, New York, NY, USA.

Silva, G. T., de Souza, J. L., e da Silva, L. A. M. (2016). Aplicação da ferramenta scratch para o aprendizado de programação no ensino fundamental i. In Anais dos Workshops do V Congresso Brasileiro de Informática na Educação (CBIE 2016). Sociedade Brasileira de Computação - SBC.

Gee, J. (2004). What Video Games Have to Teach Us about Learning and Literacy. What Video Games Have to Teach Us about Learning and Literacy. Palgrave Macmillan.

Lab, M. (2013). Scratch 2.0. https://scratch.mit.edu. [Online; acessado 31-Maio-

2017]. 
VI Congresso Brasileiro de Informática na Educação (CBIE 2017)

Anais do XXIII Workshop de Informática na Escola (WIE 2017)

Martins, L. (2016). Ensinando lógica de programação aplicada a robótica para alunos do ensino fundamental. In Anais do XXVII Simpósio Brasileiro de Informática na Educação (SBIE 2016). Sociedade Brasileira de Computação - SBC.

Matsuzaki, I. Y. e Borges, M. A. F. (2016). Ensino básico de programação para crianças e jovens com scratch. In XXIV Congresso de Iniciação Cientifica da Unicamp. Galoa.

Toffler, A. (1980). The Third Wave. Morrow.

Whitton, N. e Moseley, A. (2012). Using Games to Enhance Learning and Teaching: A Beginner's Guide. Routledge. 